\title{
EL SOMATÉN Y LA UNIÓN PATRIÓTICA EN ÁLAVA (1923-1930)
}

THE SOMATÉN AND THE UNIÓN PATRIÓTICA IN ÁLAVA (1923-1930)

Germán Ruiz Llano*

Doctor en Historia e Investigador

RESUMEN: El presente artículo estudia al Somatén y la Unión Patriótica, elementos de apoyo social y político de la Dictadura de Primo de Rivera, un período escasamente analizado de la historia del País Vasco y Álava, centrándose en sus integrantes, actuación político-social, desarrollo y causas de su fracaso final, que dio lugar al fin de la Monarquía de Alfonso XIII.

PALABRAS ClAVE: Somatén, Unión Patriótica, Dictadura de Primo de Rivera, Álava, País Vasco.

ABSTRACT: This article looks into the Somatén and the Unión Patriótica, components of the social and political support of the Primo de Rivera's Dictatorship, one historical term not much analysed of the Baske Country and Álava's history. The article analyses its components, political and social actuation, progress and the causes of its final failure, with the consequence of the end of Alfonso XIII's monarchy.

KEYWORDS: Somatén, Unión Patriótica, Primo de Rivera's Dictatorship, Álava, Basque Country.

* Correspondencia a / Corresponding author: Germán Ruiz Llano - germanruiz@ucm.es - https://orcid.org/0000-00017028-3059

Cómo citar / How to cite: Ruiz Llano, Germán (2022). "El Somatén y la Unión Patriótica en Álava (1923-1930)», Historia Contemporánea, 68, 115-137. (https://doi.org/10.1387/hc.21393).

Recibido: 19 enero, 2020; aceptado: 10 junio, 2020.

ISSN 1130-2402 - eISSN 2340-0277 / (C) 2022 Historia Contemporánea (UPV/EHU)

(c) (i) $\odot$ Esta obra está bajo una Licencia

(cc) Creative Commons Atribución-NoComercial-SinDerivadas 4.0 Internacional 
El 13 de septiembre de 1923, el general Miguel Primo de Rivera, capitán general de Cataluña, proclamó el estado de guerra en Barcelona, sublevándose contra el Gobierno de concentración liberal de Manuel García Prieto. Tras ser nombrado jefe de Gobierno por Alfonso XIII, el flamante dictador constituyó el Directorio Militar, formado por generales, instaurando un régimen de carácter militar y regeneracionista de la nación española que se prolongaría hasta enero de 1930; en el que el progreso y el desarrollo económico, el final de la crisis política, la corrupción y el caciquismo de la Restauración, la renovación de la administración, la resolución de la guerra colonial marroquí, la lucha contra el separatismo, la defensa de los valores tradicionales y el mantenimiento del orden público y social iban a ser los elementos primordiales de su programa ${ }^{1}$.

Para llevar a buen término este último punto y conseguir un elemento de apoyo y movilización de los sectores de la población afines a la naciente dictadura, la extensión del Somatén catalán al resto de España se convirtió en una de las primeras medidas del general Primo de Rivera ${ }^{2}$. Así, mediante decreto, el 17 de septiembre de 1923 se institucionalizó y comenzó su organización como un instrumento defensivo y de movilización ciudadana, que auxiliaría a las autoridades ante situaciones revolucionarias o de deterioro del orden público ${ }^{3}$ :

${ }^{1}$ Definido este último por Eduardo González Calleja como: «algo natural, inmutable e indiscutible (...) que no admite variaciones sustanciales en la hegemonía social (con la primacía de los sectores de la gran burguesía y de la nobleza que acepta las consecuencias de los cambios en sentido capitalista), el sistema político (con el establecimiento y consolidación (...) de un régimen liberal-parlamentario de sufragio restringido y con la potenciación del papel de la Corona, de la Cámara Alta y de la Administración civil y militar), y la estructura económica, con la acrítica asunción del sistema capitalista basado en la propiedad personal, libre y plena de las desiguales relaciones de producción que lleva anejas, cuyo mantenimiento era básico para el desarrollo material y la prosperidad de los grupos dominantes (...) y que quedará progresiva e indisolublemente vinculada a otra de las grandes obsesiones: el «orden público» como manifestación violenta de su dominio directo en la sociedad política». González Calleja, 1991, pp. 61-62; sobre la dictadura de Primo de Rivera, visiones generales en Ben-Ami, 2012; González Calleja, 2005; Gómez Navarro, 1991; González Calvet, 1987.

2 El Somatén era una institución cívica rural tradicional catalana que, mediante la movilización armada del vecindario local, se encargaba, desde la Edad Media, de velar por el orden público. Durante el siglo XIX su cometido se politizó al encargarse de defender al Estado liberal frente a sus enemigos carlistas. Con la llegada de la Restauración, se extendió al mundo urbano, convirtiéndose en instrumento movilizador contrarrevolucionario de las clases medias y altas barcelonesas y colaborador del Ejército en defensa del orden público y social. González Calleja y Del Rey, 1995, pp. 55-103.

3 Gaceta de Madrid. 18-IX-1923. 
En el Instituto de Somatenes de Cataluña, organismo de rancio y glorioso abolengo español, se reúnen todos aquellos hombres de buena voluntad, amantes del orden y celosos de sus deberes ciudadanos.

La recia estirpe de esta organización cívica y la briosa historia de sus hechos, en la paz y en la guerra, han creado en los Somatenes catalanes aquella honrada solidaridad y aquel vigor espiritual tan necesarios en las colectividades cuyo fin primordial es la conservación de la paz pública.

En todas las regiones españoles podrían contar las Autoridades con un tan poderoso auxilio si en las provincias que las constituyen se crease el Somatén, organización que no sólo se ciñe a dar fuerza y vigor al espíritu ciudadano, sino que separando de los ánimos la pasividad y la indiferencia, los moviliza en el significado de la insustituible palabra som-atent: Estamos atentos.

Si bien en aquellos primeros momentos el dictador quiso trazar paralelos entre el Somatén y los fascios di combattimento italianos, conviene recalcar las principales diferencias entre ambos. Por un lado, el Somatén era impulsado desde una dictadura militar como medio de defensa y movilización ciudadana. En él tenían cabida todas las ideologías de «orden» para hacer frente a los desórdenes públicos, formándolo personas de edad madura. Mientras que, por su parte, los fascios eran una milicia política formada mayoritariamente por personas jóvenes y estaban concebidos como un instrumento agresivo y subversivo para la toma del poder ${ }^{4}$. El Somatén estaría en todo momento subordinado a la autoridad militar y en él se admitiría a toda persona mayor de 23 años con «reconocida moralidad» que pudiera costearse su arma ${ }^{5}$. Asimismo, sus miembros tendrían el status de fuerza armada en caso de que se proclamase el estado de guerra y de agentes de la autoridad en el resto de situaciones ${ }^{6}$.

En Álava, la organización del Somatén comenzó el 2 de octubre de 1923, con la publicación de un bando por parte del general Felipe Enciso,

${ }^{4}$ González Calleja y Del Rey, 1995, pp. 167-169; González Calleja, 1999, pp. 294296; Quiroga, 2008, pp. 276-277.

5 Por ejemplo, en Vitoria, desde su Ayuntamiento, se pidieron informes a la Guardia Municipal sobre los solicitantes locales, remitiéndolos a la Jefatura de los Somatenes de la

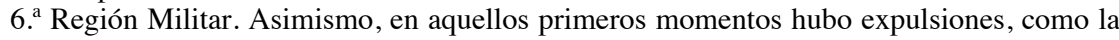
de Teodoro López, maestro de la localidad de Cripán, admitido en el Somatén el 21 de noviembre de 1923, y del que el 14 de diciembre se pidieron informes al cabo del distrito de Laguardia, que debieron ser negativos, ya que fue dado de baja el día 20. AMVG. 25-6-68; ATHA. Fondo Enciso. Libro de comunicaciones del Somatén del Distrito de Laguardia.

${ }^{6}$ Gaceta de Madrid. 18-IX-1923. 
gobernador militar de la provincia al advenir el golpe, y civil desde el 19 de septiembre, en el que encarecía la participación en su constitución de ${ }^{7}$ :

... las personas de más arraigo por su posición social, los patronos de las grandes industrias, los propietarios de fincas rústicas y urbanas, Cámaras de Comercio, Ateneos científicos o culturales, directores de bancos y empresas financieras, en una palabra, cuantos influyen en la vida económica e intelectual del país.

Tras este llamamiento, las fuerzas vivas locales cogieron el guante y el 4 de octubre de 1923 se celebró una primera reunión organizativa presidida por el general Enciso. En ella se barajaron los nombres de los candidatos para el puesto de vocal que le correspondía a Álava en la comisión organizadora de los somatenes de la $6{ }^{\text {a }}$ Región, y el día 12 hubo otra para estudiar las propuestas de los cabos y subcabos de distrito, dirigiendo los trabajos organizativos el teniente coronel de Estado Mayor Antonio Gudín, instalándose su oficina en una dependencia del Gobierno Militar ${ }^{8}$. A los pocos días, el comandante de infantería José Limón y el industrial carlista y presidente de la Cámara de Comercio Moisés Ruiz de Gauna, fueron nombrados, respectivamente, auxiliar militar del Somatén vitoriano y vocal de la comisión de la 6. ${ }^{a}$ Región. Como se puede observar, la subordinación del Somatén a las autoridades militares quedaba clara en todo momento ${ }^{9}$.

Paralelamente, comenzaba una campaña por parte del Heraldo Alavés (diario católico y portavoz del conservadurismo provincial), animando el ingreso en el Somatén, afirmando las ventajas para los afiliados y las bondades para la sociedad de la nueva institución ${ }^{10}$ :

La investidura de autoridad que recibe el somatenista desde el punto en que es admitido como tal autoridad que ejercerá en el momento preciso de alteración del orden, de la comisión de un delito contra las per-

7 Boletín Oficial de la Provincia de Álava. 4-X-1923.

8 Participaron en la primera reunión «el Provisor de la Diócesis, Presidente de la Audiencia, el Presidente, en funciones, de la Diputación, Director del Instituto, alcalde, Delegado de Hacienda, Presidentes de las Cámaras de Comercio y de la Propiedad, director del Banco de España, Registrador de la Propiedad, Presidente de la Sección de la Cruz Roja, Banco de Bilbao, de Vitoria, de Vizcaya y Urquijo, Sindicato Católico Agrícola, Federación de Sindicatos Católicos, Real Ateneo regio de Instrucción Pública, Representación del Cabildo [de la] Catedral y otras distinguidas personalidades». Heraldo Alavés. 5-X-1923.

9 Heraldo Alavés. 5, 12, 15, 16 y 23-X-1923; La Libertad. 5 y 12-X-1923.

${ }_{10}$ Heraldo Alavés. 16, 18, 24 y 30-X-1923; 2-XI-1923. 
sonas o contra la propiedad; en la persecución de malhechores y las facultades que su condición de somatenista le da, son circunstancias que aconsejan a toda persona prudente el alistamiento.

(...)

Consideren los remisos la obligación moral en que se hallan y procuren enterarse de la importancia enorme que para España supone la cooperación que el Gobierno solicita.

Al poco, comenzó la publicación por parte de la prensa de los listados de los solicitantes admitidos entre 1924 y 1925, 1.541, el 3,1\% de la población masculina de la provincia, una afiliación por encima de la media nacional. Posteriormente, los ingresos continuarían, pero de manera marginal en paralelo a la decadencia de la Dictadura ${ }^{11}$. A través del estudio de aquellas afiliaciones se puede observar que entre los somatenistas se encontraban los sectores más afectados por el miedo revolucionario de aquellos años tras la Revolución Rusa en 1917 y la crisis económica de la posguerra mundial. Por un lado, las clases altas y medias urbanas y por otro el mundo rural tradicional formado por pequeños propietarios católicos, teniendo mucho más éxito en el segundo ámbito que en el primero ${ }^{12}$. En este sentido, el Sindicato Católico Agrícola Alavés (SCAA), la principal asociación de labradores de la provincia, apoyó a la Dictadura y animó a sus miembros a inscribirse en el Somatén con el fin de defender la propiedad privada y el orden público ${ }^{13}$ :

Uno de los servicios que (...) los labradores estimáis en mucho es el de la guardería rural y por eso en Álava donde los pueblos son muy pequeños, se asocian tres o más para establecer guardas jurados que les protejan sus frutos de las rapacerías de las malas gentes.

Este servicio, grandemente ampliado a las personas y a las cosas, viene a cumplir el Somatén.

En las ciudades es oportunísimo en estos tiempos de latrocinio sistemático y violencia organizada; en las aldeas donde por una parte se falta

11 Vélez, 2017, pp. 361-363.

12 En el municipio de Vitoria sólo se han localizado 237 somatenes, con lo que la desproporción entre ambos ámbitos es evidente. Sobre los miedos revolucionarios de esos sectores sociales durante aquellos años Rivera y De Pablo, 2014, pp. 274-305.

${ }^{13}$ El SCAA, pertenecía a la Federación Católico-Agraria y tenía como fin promover los intereses de los labradores alaveses, la adquisición de abonos y maquinaria para los socios, etc. Sanz Legaristi y Reboredo Olivenza, 1985, pp. 90-104; su apoyo a la Dictadura y el llamamiento para inscribirse en el Somatén en El Porvenir Agrario. ‥.$^{\circ} 32$ y 33. 
también cada día más descaradamente a los preceptos de justicia y por otra parte falta la Policía y escasea la Guardia Civil, es indispensable.

Por este motivo es de recomendar que los labradores alaveses se afilien a la institución del Somatén con la conciencia del deber patriótico y del amor propio bien entendido.

También se inscribieron varios sacerdotes, los cuales legitimaban al Somatén y le prestaban apoyo ideológico, sobre todo en el mundo rural, donde eran figuras muy influyentes en la vida local, encontrando el nuevo régimen el apoyo de la Iglesia desde los primeros momentos ${ }^{14}$. Así, en la circular del Obispado de Vitoria del 9 de octubre de 1923, se celebraba la creación del Somatén y su lucha contra la «blasfemia y la pornografía, esas dos plagas terribles que han invadido la sociedad», instando a los sacerdotes de la Diócesis a colaborar en su reclutamiento entre los feligreses de sus parroquias ${ }^{15}$ :

Nos dirigimos a vosotros, Venerables Hermanos y fidelísimos cooperadores en la misión pastoral que el cielo nos ha encomendado, para que sin pérdida de tiempo forméis en vuestras feligresías listas de hombres honrados que mejor hayan de servir al noble fin que con la creación del Somatén se pretende, y, bien los entreguéis a los respectivos jefes de la benemérita Guardia Civil, bien los remitáis al Gobierno Militar de vuestra provincia, para que, al mismo tiempo que principalmente veláis por la causa de la religión, ofrezcáis a la patria hombres de probada garantía que ayuden a las autoridades a exigir de todo ciudadano el cumplimiento de las leyes a que está obligado.

En este sentido, por ejemplo, en el pueblo de Elvillar se achacó la alta implantación del Somatén y las adhesiones a la Unión Patriótica (UP) a la actuación e influencia de su sacerdote, Baldomero Guinea, debido a sus

${ }^{14}$ En el apoyo de la Iglesia influyó decisivamente el hecho de que el Gabinete de García Prieto tenía entre sus proyectos de reforma el que el patrimonio artístico, incluyendo el eclesiástico, pasara a manos del Estado y, más importante aún, quería reformar la Constitución de 1876 y permitir la celebración de actos de culto públicos no católicos. Durante la Dictadura, la Iglesia ocuparía un lugar de privilegio dentro de la sociedad española, recuperando ciertas prerrogativas como la libertad para elegir obispos y arzobispos y aumentaría su influencia en la educación. El apoyo del Obispado de Vitoria y las oraciones y actos religiosos públicos a favor del nuevo régimen en Heraldo Alavés. 5 y 13-X-1923; Boletín Oficial del Obispado de Vitoria. 1-X-1923; 2-XI-1923; De Pablo, Goñi y López de Maturana, 2013, pp. 242-245; el intento reformista de García Prieto en González Calvet, 1987, pp. 98-99; las relaciones Iglesia-Estado durante la Dictadura en González Calleja, 2005, pp. 94-99.

${ }^{15}$ Boletín Oficial del Obispado de Vitoria. 2-XI-1923. 
iniciativas en pro del resurgimiento de la vida religiosa y diversas actividades de carácter económico, cultural y social a favor de su vecindario ${ }^{16}$.

Por su parte, los obreros asalariados y jornaleros agrícolas son escasos, no obstante los llamamientos interclasistas del dictador. Como el realizado en el comunicado enviado al comandante general del Somatén de la $6 .{ }^{\text {a }}$ Región, afirmando que ${ }^{17}$ :

En el Somatén caben los hombres todas las ideas políticas y solo la obcecación puede tachar de retrógrada o tiránica a una institución que tiene por lema paz, justicia y orden, que son los tres postulados de la verdadera democracia.

Las causas de ello serían tanto por ideológicas como por el requisito de tener que costearse su propia arma, ya que por ejemplo, en Elvillar, 17 solicitantes admitidos en el Somatén renunciaron a su ingreso por «carecer de recursos para adquisición de armas». Mientras que en las localidades de Yécora y Zambrana había somatenistas que carecían de ellas ${ }^{18}$.

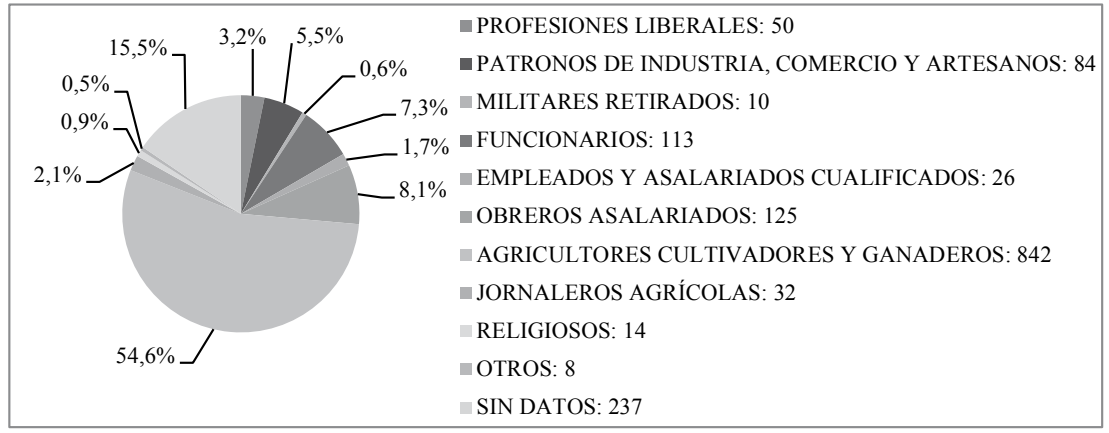

\section{Gráfico 1}

Origen socio-profesional del somatén Alavés ${ }^{19}$

${ }^{16}$ Heraldo Alavés. 19-VII-1924.

17 Heraldo Alavés. 4-II-1924.

18 ATHA. Fondo Enciso. Libro de comunicaciones del Somatén del Distrito de Laguardia.

19 Elaboración propia a partir de Heraldo Alavés y La Libertad. 1923-1925; ATHA. Censo electoral de 1925. Tomo como referente de clasificación socio-profesional, con alguna variación, la usada en Sanz Legaristi, 1985. 
Aunque no es posible conocer la filiación política anterior a su ingreso de la inmensa mayoría de los somatenistas, se ha podido averiguar la que tenía una parte significativa de ellos durante la II República. De su análisis se concluye que en el Somatén se agruparon todos los sectores de las derechas y el conservadurismo de la provincia, incluyendo un importante porcentaje de nacionalistas vascos, pero que el carlismo era hegemónico. Por su parte, quienes se inclinaron más adelante por la militancia en las fuerzas republicanas, se decantaron de manera general por sus formaciones más moderadas, como el Partido Republicano Radical, siendo marginales quienes optaron por opciones más a la izquierda, que se circunscribieron exclusivamente al Partido Socialista o la Unión General de Trabajadores.

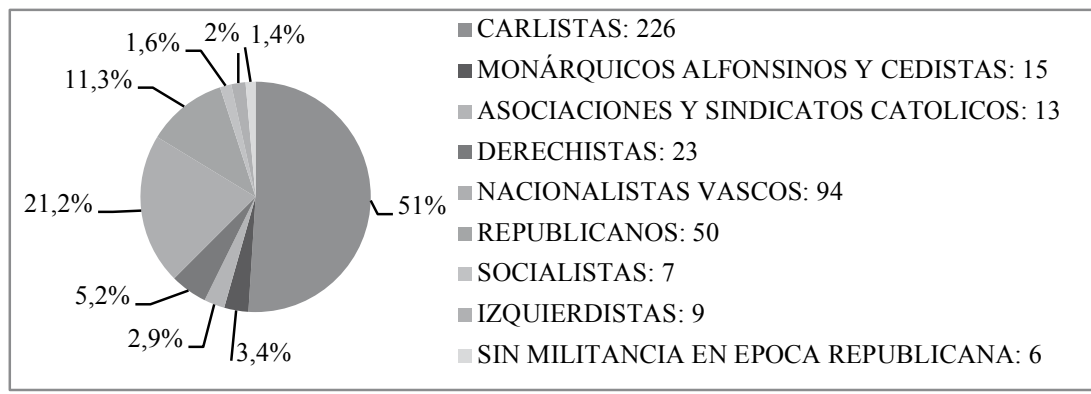

\section{Gráfico 2}

Filiación político-asociativa de los somatenes alaveses durante la II República ${ }^{20}$

En cuanto a los cabos y subcabos de partido judicial y los diferentes ayuntamientos, los perfiles buscados serían, en palabras del teniente coronel Gudín, «previo informe de la Guardia civil, (...) los vecinos de mayor arraigo y prestigio», correspondiendo a personas de clase alta o «notables» locales, habiendo realizado algunos de ellos anteriormente incursiones en política dentro del campo de la derecha católica. Así, por

${ }^{20}$ Elaboración propia a partir de AHPA; ATHA; Heraldo Alavés. 1931-1932; Pensamiento Alavés. 1932-1936; Euzkadi y La Libertad. 1931-1936; Álava Republicana. 19351936. No se tienen en cuenta los 1.098 somatenes de los que no he podido hallar datos. 
ejemplo, el cabo y el subcabo del partido judicial de Vitoria, Guillermo Montoya y Marceliano Ruiz de Eguílaz, al advenir el golpe, eran respectivamente, concejal del Consistorio vitoriano por la ultraconservadora Unión Popular Católica, y diputado provincial y presidente del SCAA ${ }^{21}$.

\section{Cabos y subcabos del somatén de partido judicial y ayuntamiento}

\section{Partido Judicial de Vitoria:}

Cabo Guillermo Montoya Eguinoa, abogado.

Subcabo Marceliano Ruiz de Eguílaz, labrador.

Partido Judicial de Amurrio:

Cabo Manuel Eguileor Urraza, sin datos.

Subcabo Ángel Larrea Galindo, propietario $^{22}$.

Partido Judicial de Laguardia:

Cabo Vicente Enciso Aguirre, banquero.

Subcabo Ángel Ayala González de Junguitu, notario.

A lo largo de la Dictadura, el Somatén se fue instaurando progresivamente por toda la provincia mediante ceremonias de entrega de banderas o de creación, en las que se hizo patente la promoción que de él hacían las clases altas y personas de orden locales y provinciales. El ritual propagandístico de aquellos actos ejercía como elemento movilizador de la población a favor de la Dictadura y los valores que defendía, siendo usualmente el mismo: recibimiento de las autoridades civiles y militares provinciales, revista de la formación del Somatén local, una misa, discursos de las autoridades, bendición de la bandera por parte del clero local con intervención de la correspondiente madrina, normalmente hijas o esposas de la buena socie$d a d$, desfile de los somatenes y un banquete con el que finalizaba el acto ${ }^{23}$.

21 La Libertad. 12-X-1923; Rivera y De Pablo, 2014, pp. 293-305.

22 En 1927 sería secretario de la Asociación de Propietarios de Llodio, cuyo lema era «Defensa de la propiedad urbana, rústica y pecuaria», muy en consonancia con su militancia somatenista. AHPA. 27446-A.

23 Actos en las localidades de Vitoria, La Libertad y Heraldo Alavés. 8-IX-1924; Elburgo, Heraldo Alavés. 1-VII-1924; Peñacerrada, La Libertad. 1-VII-1925; Llodio, Heraldo Alavés. 15-IX-1924; Nuevo Mundo. 9-IX-1924; Lapuebla de Labarca, Heraldo Alavés. 16-II-1925; La Libertad. 17-II-1925; Valdegovía, Heraldo Alavés. 8-XI-1929; Fontecha, Heraldo Alavés. 1-V-1928; Nanclares de la Oca, Heraldo Alavés. 2-X-1928; Cuartango, Heraldo Alavés. 9-VI-1928; Moreda, Heraldo Alavés. 22-V-1925; sobre la significación nacionalista española y como propagadoras de la ideología de la Dictadura de estas ceremonias en Quiroga, 2008, pp. 271-281. 
Las actividades de los somatenistas alaveses fueron más bien limitadas y de tipo propagandístico ${ }^{24}$. Sin verdaderos peligros para el orden público a la vista, se circunscribieron a desfilar o presentar armas con ocasión de visitas de autoridades o personalidades, las revistas e inspecciones, la fiesta de su patrona (la Virgen de Montserrat), juras de bandera de reclutas y las victorias en Marruecos, intervenciones en reyertas vecinales o detención de criminales, denuncias de infracciones de furtivismo, juego ilegal, blasfemias, etc. y ayudar al vecindario con ocasión de incendios o accidentes. Tampoco faltaron abusos de autoridad o enfrentamientos por el poder local, lo que pudo motivar un cierto desprestigio en las zonas rurales ${ }^{25}$.

En paralelo a la progresiva organización del Somatén, en diciembre de 1925, el general Primo de Rivera, con la intención de institucionalizar su régimen, constituyó el Directorio Civil, dando cabida a civiles en las responsabilidades ministeriales. Para ello, intentó cimentar un apoyo popular y de masas a través de la UP, concebida, nacida e impulsada como partido único y plataforma para agrupar a todos los afines a la Dictadura, ayudar a su institucionalización y legitimización, realizar labores propagandísticas y movilizadoras y proveer del personal necesario para los cargos públicos.

En Álava, la primera mención a su creación apareció en prensa el 24 de abril de 1924, con el anuncio por parte de Pedro de la Brena (gobernador civil de la provincia de abril a noviembre de 1925), de las gestio-

${ }^{24}$ Es posible que por esa causa una parte de sus afiliados no se tomaran muy en serio sus deberes. Sobre todo si debían poner dinero de su bolsillo o realizar un esfuerzo personal más allá de asistir a las celebraciones y juras de bandera, ya que por ejemplo, en febrero de 1925, 41 somatenes del distrito de Laguardia fueron dados de baja por no suscribirse al Boletín de Somatenes de la $6 .^{a}$ Región, cuyo coste era de tres pesetas anuales. ATHA. Fondo Enciso. Libro de comunicaciones del Somatén del Distrito de Laguardia.

25 Actuaciones con ocasión de robos, riñas vecinales, blasfemias, etc. en Amézola, 1929, pp. 32-34; Heraldo Alavés. 6 y 13-VI-1924; 4-VII-1924; 2-X-1926; 6-XII-1926; 21V-1927; La Libertad. 22-XI-1926; 23-V-1927; 9-VI-1927; 13-V-1929; participación en juras de bandera de reclutas, despedida de tropas expedicionarias y celebraciones de victorias en Marruecos en Heraldo Alavés. 24-III-1924; 8-VII-1924; 13-II-1925; 6-X-1925; asambleas, conferencias, actos de revista y celebraciones de todo tipo en La Libertad. 30IV-1925; 27-IV-1927; 10, 19 y 24-V-1928; Heraldo Alavés. 18 y 25-II-1924; 14-VII-1924; 9-III-1925; 30-IV-1925; 24-II-1926; 22-III-1926; 19 y 27-IV-1926; 21-XII-1926; 25-IV1927; 9 у 17-V-1927; 23-IX-1927; 17-XI-1927; 30-IV-1928; 4, 16, 21 у 23-V-1928; 22VIII-1928; 13-V-1929; 5-VI-1929; enfrentamientos entre somatenistas y abusos en $\mathrm{He}$ raldo Alavés. 1-VII-1924; 8-XI-1924; La Libertad. 2-VII-1924. 
nes organizativas realizadas por parte del médico José Pérez-Agote. A los pocos días, el 6 de mayo, se hizo público el manifiesto del Comité de organización de la UP alavesa, invitando a una colaboración interclasista y transversal ideológicamente, en parecidos términos a los expresados con el Somatén, pero siempre dentro de los parámetros conservadores de la Dictadura $^{26}$ :

Nuestra misión va encaminada únicamente a reunir todo lo más sano, PROVENGA DE DONDE PROVENGA, que para nosotros no hay distingos con tal de que acepta lo que todo buen ciudadano tiene que aceptar; familia, propiedad, Patria y Monarquía, ideales que no se conciben sin la fe religiosa, para emprender la obra magna de formación de una Patria grande... de una España en cuyos dominios, sino materiales, espirituales, no se ponga el sol...

En nuestro campo no hay clases, una cristiana fraternidad unirá al obrero de la inteligencia con el obrero manual, al ignorante de corazón recto con el sabio de buena voluntad, al propietario con el colono, a los gobernantes con los gobernados, al magistrado, al sacerdote, al militar... en una palabra TODOS caben en ella y a TODOS LLAMAMOS para que juntos emprendamos nuestra obra.

Tal y como aconteció con el Somatén, a los pocos días comenzaron a publicarse en la prensa relaciones abultadísimas de afiliados, sobre todo provenientes de los pueblos, que en ciertos casos incluirían a todos los cabezas de familia de algunas localidades, llegando oficialmente a alcanzar los 12.000 en $1927^{27}$. Esta masiva afiliación del mundo rural tendría varias causas. Sin olvidar la afinidad ideológica que podían tener parte de los afiliados o la necesidad de estar a bien con el régimen por parte de los numerosos funcionarios públicos que aparecieron en los listados, la militancia conllevaba beneficios personales, como el acceso a las concejalías y puestos de responsabilidad ${ }^{28}$. También influía el nulo nivel de compromiso y la casi gratuidad de las cuotas de afiliación (una peseta anual), así como las posibles coacciones o recomendaciones que podía recibir el vecindario de las diferentes localidades por parte de personas influyentes, patrones, alcaldes

26 Heraldo Alavés. 6-V-1924.

27 Alonso, 1927, p. 206.

$28 \mathrm{Al}$ respecto, no resulta casual que en el municipio de Aramayona, al designarse el Comité local de la UP, Pablo Cortabarría, uno de sus vocales, fuera nombrado al mismo tiempo secretario del Ayuntamiento. Heraldo Alavés. 9-VII-1927. 
o los secretarios de los ayuntamientos ${ }^{29}$. De hecho, según afirmó Ladislao de Amézola, dando al traste con el discurso anticaciquil de la Dictadura ${ }^{30}$, las viejas élites rurales se afiliaron a la UP en masa ${ }^{31}$ :

En los municipios rurales, militan en sus filas, las personas de mayor prestigio y valía por su competencia y desinterés; de tal modo que, prácticamente, todas las fuerzas vivas le han dado su nombre, y cuantos tienen verdadera independencia, se han afiliado a ella, constituyendo una valiosa reserva en defensa del orden y la moralidad administrativa.

Afirmación que se puede corroborar en los listados publicados en la prensa. Por ejemplo, en el del municipio de Urcabustaiz, entre otros, aparecen el alcalde, un ex-alcalde, el teniente de alcalde, el secretario del ayuntamiento, cuatro concejales, el alguacil municipal, el capataz del ferrocarril y el de los peones camineros, el cabo y el sub-cabo de los somatenes, cuatro maestros, seis sacerdotes, el médico, el juez municipal, el veterinario, el fiscal municipal, el presidente de la sección local del SCAA, dos funcionarios y cinco alcaldes de barrio o presidentes de juntas administrativas de las localidades que componían el municipio ${ }^{32}$.

Por su parte, en Vitoria la UP tuvo una vida anémica, siendo la actitud de la población urbana más bien indiferente, mientras que la rural permanecía pasiva. Según el testimonio de Tomás Alfaro ${ }^{33}$ :

...la Unión Patriótica no tuvo mucho arraigo en Vitoria. Fue una agrupación enquistada e impuesta desde arriba que nunca llegó a extenderse con pujanza. Los carlistas tenían la suya firmemente asentada, y los demás, apolíticos o conservadores claudicantes, no hacían número que pesara.

Debido a ello, en diciembre de 1925 la asamblea provincial upetista acordó intensificar los actos propaganda para atraer nuevos afiliados, y a

29 Gómez Navarro, 1991, pp. 231-236.

${ }^{30}$ Por ejemplo, desde Heraldo Alavés se afirmó lo siguiente: «La significación de la Unión Patriótica es esencialmente anticaciquil. Su característica es la enemiga a todo caciquismo. El Presidente del Directorio ha tenido especial empeño en afirmarlo en ocasiones repetidas. La Unión Patriótica viene recoger con una actuación política de impoluta diafanidad el gesto viril de un militar pundonoroso trazó, el 13 de Septiembre último, el primer peldaño de la renovación de la vida política española». Heraldo Alavés. 14-VI-1924.

31 Amézola, 1929, p. 44.

32 Heraldo Alavés. 24-V-1924.

33 Alfaro, 1995, p. 39. 
lo largo de 1927 se realizaron en la prensa llamamientos públicos a la movilización ciudadana, lo que desmentiría las abultadas afiliaciones hechas públicas anteriormente ${ }^{34}$.

En paralelo, la organización de la UP tuvo que enfrentarse a la campaña de prensa en contra de sus responsables, bajo la acusación de ejercer el caciquismo, emprendida por el liberal Luis Dorao, director del periódico La Libertad y diputado provincial. La causa fue la integración en ella de rivales políticos suyos durante los años anteriores. El principal era José Pérez-Agote, nombrado jefe provincial en agosto de 1924, y cuyo hermano José Joaquín había sido candidato a Cortes por el distrito de Laguardia en las elecciones de 1923, donde Dorao tenía influencias y apoyaba al candidato republicano Enrique Ocio, resultando aquellas tumultuosas, con denuncias de fraude y coacciones de todo tipo ${ }^{35}$.

Tras el primer llamamiento público, comenzó una campaña de actos para iniciar la organización de las diferentes secciones locales upetistas y dar a conocer ante la opinión pública y potenciar la imagen de José Pérez-Agote, cuyo perfil personal y político nos lo ofrece el testimonio de Tomás Alfaro ${ }^{36}$ :

34 La Nación. 9-XII-1925; La Libertad. 15-II-1927; 10 y 31-VIII-1927; Heraldo Alavés. 5-IV-1927; 7-V-1927; 30-VIII-1927.

35 Dorao sería cesado como diputado provincial en marzo de 1925, seguramente como resultado de esa campaña y otras emprendidas en contra de los abusos e irregularidades realizadas por los partidarios de la Dictadura en las instituciones. La revancha de PérezAgote llegaría en noviembre de aquel año, cuando informó desfavorablemente al Ministerio de la Gobernación al barajarse la posibilidad de que pudiera revocarse su cese. No obstante, al respecto, tampoco faltó prepotencia por parte de Dorao, ya que el 7 de noviembre se informaba desde el Ministerio de la Gobernación al gobernador De la Brena, que «En vista antecedentes recibidos y seguridades que da el señor Dorao, de que [se abstendrá] de toda campaña que pueda molestar (...) puede reponerle en el cargo de Diputado provincial». Sin embargo, el día 26, se informaba lo siguiente desde Vitoria, «cuando se había acordado que podía ser repuesto, y antes de serlo, siguió haciendo campaña contra el gobernador, atribuyéndose como un triunfo personal la probable salida de Vitoria del mismo, produciendo con ello incidentes desagradables y escribiendo cartas un tanto inconvenientes y destempladas, todo lo cual ha traído como consecuencia la dimisión, ya aceptada, [de De la Brena]». AHN. Gobernación. Leg. 19 A; lo de José Joaquín Pérez-Agote en Pérez Agote, 1923; Rivera y De Pablo, 2014, p. 300; las denuncias y acusaciones de caciquismo contra los responsables de la organización de la UP en La Libertad. 9, 24 y 26-V-1924; 4-VI-1924; 6, 20, 26, 27, 28 y 29-VIII-1924; 3-IX-1924; 17-XII-1924.

36 Alfaro, 1995, pp. 39-40; los actos y mítines de propaganda y organización de la UP en Heraldo Alavés. 2 y 3-VI-1924; 5 y 26-VIII-1924; 21-XI-1925; 7-XII-1925; el nombramiento de Pérez-Agote como jefe de la UP y la campaña de prensa para darlo a conocer, en Heraldo Alavés. 7-VI-1924; 7-VII-1924; 5 y 26-VIII-1924; 14-X-1924; 1-VI-1925; La Libertad. 6-VIII-1924. 
...llegado algunos años antes a Vitoria, con fama de hábil cirujano, quien había sabido introducirse en la ciudad, dando paso tras paso con cauto acomodamiento en el ambiente de «respetabilidad» del dinero y de la distinción social, le fue adjudicada la Presidencia en Álava. Pérez Agote era inteligente, de vida ponderada y activo en su profesión, donde pronto alcanzó relevante puesto. Sin antecedentes políticos conocidos, se mostraba como derechista a ultranza, lindando con el carlismo, y así logró, sin definirse demasiado, captar a unos y a otros, en la neblina de la ambigüedad (...) Con ambigüedades tendentes a lo «patriótico» y con el apoyo decidido del Obispo, entonces Monseñor fray Zacarías Martínez, de quien recabó y obtuvo autoridad, y con gran parte del clero a su lado, extendió, el doctor Agote, sus redes hacia el nacionalismo vasco, y en ellas logró enredar a algunos de sus capitostes, valiéndose de ser oriundo de Zumaya y hablar vascuence a la perfección.

En este sentido, Pérez-Agote y buena parte de los principales miembros de la UP, derechistas independientes, católicos y una parte de los tradicionalistas, tanto provenientes del carlismo como de sus diferentes escisiones, formaban parte de los «hombres nuevos». Estos provenían de sectores marginados del mundo político durante la Restauración y saltarían a este durante la Dictadura. Tal y como señalan Gómez Navarro y De Pablo y Rivera, tanto a nivel nacional como provincial, y que en el País Vasco tuvieron mucha influencia en la UP al retraerse buena parte de las élites monárquicas liberales restauracionistas de participar en las creaciones de la Dictadura, ya que por su ideología se distanciaron de esta o disponían de acceso directo tanto al dictador como a Alfonso XIII para defender sus intereses, llegando a rivalizar con estas nuevas élites en algunos $\operatorname{casos}^{37}$. En este sentido, Álava no fue una excepción y los líderes más importantes de los partidos monárquicos liberales se retrajeron de colaborar con la UP. Según el testimonio de Tomás Alfaro ${ }^{38}$ :

...[la UP se topó con] la barrera de liberal, tras la que seguían manteniéndose fuerzas estimables, familias monárquicas de abolengo aristocrático, Aragones y Elíos sobre todo, y otras, burguesas de industriales y comerciantes acomodados, muchas de raigambre republicana moderada.

37 Rivera y De Pablo, 2014, p. 310; Gómez Navarro, 1991, pp. 242-244 y 250-260; Arana, 1982, pp. 71-85.

38 Alfaro, 1995, p. 40. 
En cuanto a su funcionamiento interno, la UP alavesa se caracterizó por la dependencia del apoyo oficial ${ }^{39}$, la pasividad y la autoridad omnímoda de Pérez-Agote, que decidía sobre todos los aspectos y nombramientos. La situación era tan poco halagüeña que Antonio Tomás Hernández (gobernador civil de diciembre de 1925 a agosto de 1926) informó al general Severiano Martínez Anido, ministro de la Gobernación, el 2 de junio de 1926 que $^{40}$ :

La U.P. de aquí no existe más que de nombre, porque no hacen acto alguno de propaganda, ni de señas de nada, hasta el punto de que el Comité provincial no se reúne, ni se ha reunido ahora para la designación de estos señores [hace referencia a informes para candidatos para gobernadores civiles], si no que los ha designado por si sólo el Sr. Presidente de la U. P. siento tener que hacer a V. I. estas manifestaciones, pero me creo en la obligación de hacerlo, e indicarle también que dos sres del Comité que presentaron la dimisión, todavía no les han dado de baja, ni se ha reunido el Comité para admitírselas, y esta así desde el mes de marzo. Como yo no puedo inmiscuirme en los asuntos de la U. P. nada puedo hacer, ni el Sr. General Gil Yuste [gobernador militar] tampoco, pues los actuales directores, ni harán ni dejarán hacer.

También se produjo un enfrentamiento público entre Pérez-Agote y Tomás Hernández, ya que tras una primera reunión efectuada con el Comité provincial de la UP el 21 de enero de 1926, se publicó en la prensa al día siguiente una nota oficiosa firmada por este último que afirmaba lo siguiente ${ }^{41}$ :

El señor Agote, en forma sucinta y concreta, explicó al señor Gobernador cómo empezó a formarse en esta provincia el partido U. P.; de la propaganda realizada por él y señores del Comité que se honra en presidir; de la forma de organización dada; del número de afiliados que la integran y de la actuación del partido en ésta, expresándose acerca de esto

39 Por ejemplo, la Junta Directiva provincial y la municipal de Vitoria, se reunían, respectivamente, en el Gobierno Civil y el Ayuntamiento, y aunque desde diciembre de 1925 se había hecho constar públicamente la conveniencia de adquirir un local propio, la UP no lo tuvo hasta enero de 1928. Describiéndolo Alfaro como un lugar «con muebles raídos aunque poco usados, porque allí no acudía nadie que representara nada, a no ser algún alcaldillo de pueblo a recibir instrucciones». Alfaro, 1995, pp. 77-78; La Libertad. 16-XII1925; Heraldo Alavés. 2-I-1928.

40 AHN. Gobernación. Leg. 37 A.

${ }^{41}$ La Libertad. 22-I-1926. 
último por el señor Gobernador la extrañeza que le causaba no ver los frutos de dicha actuación en hechos ya cristalizados, exponiéndose seguidamente por el señor Agote las causas de ello, que escuchadas atentamente por el señor Hernández fue motivo de que por éste se exteriorizara su más decidido propósito de que U. P. actúe en esta provincia como órgano de gobierno y para que su completo desenvolvimiento y eficacia pondrá en juego no sólo su actuación personal, sino que también aquellos medios de gobernante necesario, siempre dentro de la mayor equidad y justicia.

En paralelo, se produjo otro enfrentamiento entre Tomás Hernández y el SCAA debido a una serie de denuncias por irregularidades en la gestión de sus fondos y choques entre los socios. El choque se agravó hasta el extremo de solicitar Tomás Hernández al general Martínez Anido el 7 de julio de 1926 el cese de toda su Junta Directiva, que pertenecía en pleno al Somatén y la UP'2:

En este y en todos los casos que se presentan en esta provincia hay que obrar con toda energía porque están acostumbrados muy mal, a hacer lo que les da la gana, por esto se precisa para poder extirpar el caciquismo sentar la mano, y como yo no me he prestado a supeditarme a ellos, por eso los caciques, que son los mismos que antes y amparados por los mismos, no me quieren de Gobernador, en cambio, los que demandan cosas justas (...) están satisfechos de mi gestión. Permítame V.E. estas manifestaciones y expansiones porque la negativa a la advertencia mía de la celebración de la Junta General me ha traído a la memoria la campaña solapada e infundada de los caciques han hecho contra mí...

De hecho, el cese de Tomás Hernández se produjo el 6 de agosto, seguramente por los deseos del Directorio Civil de calmar la situación y a los manejos de sus enemigos de la UP y el SCAA, que enviaron, respectivamente, en marzo y mayo de 1926 delegaciones a Madrid para solicitar su traslado ${ }^{43}$. Todo ello a causa de la enérgica gestión y personalidad de Tomás Hernández, que incluyó duros discursos y la censura pública de la gestión de algunas instituciones nada más hacerse cargo del Gobierno Civil, como el efectuado en el Consistorio vitoriano, y la denuncia de la situación de la UP ${ }^{44}$.

42 AHN. Gobernación. Leg. 67 A; el inicio del enfrentamiento con el Sindicato Agrícola en La Libertad. 23 y 26-III-1926.

${ }^{43}$ La Libertad. 20-III-1926; 22-V-1926.

${ }^{44}$ Parece que ya en el mes de junio Martínez Anido tenía la intención de cesarlo, recibiendo un informe sobre el que sería su sustituto, Ladislao de Amézola, que afirmaba 
Con la llegada del nuevo gobernador, Ladislao de Amézola, que permaneció en el cargo hasta enero de 1930, la tranquilidad dentro de los engranajes de la Dictadura volvió ${ }^{45}$. Sin embargo, tal y como reconoció públicamente en 1928, la UP no consiguió salir de su parálisis ${ }^{46}$ :

En la capital cuenta con un gran núcleo que incluye a fuertes industriales, comerciantes, propietarios, intelectuales, trabajadores, etc., pero faltan muchos que por su ideología simpatizan con ella, no pocos cuya atonía les impide colaborar por sus fines, y otros que le son francamente hostiles. Su actuación se halla unida todos los actos de resonancia que tienden a robustecer al Gobierno; ella recogió en 1927 muchos millares de firmas de personas de ambos sexos adhiriéndose al Gobierno; ella organizó un tren especial a Madrid y facilitó el desfile de 500 alaveses por las calles de Madrid en la grandiosa manifestación del 13 de septiembre de 1928, en homenaje al ilustre Jefe del Gobierno, y enviando a Madrid más de 20.000 pesetas ofrendadas por los alaveses. Actualmente (...) abriga proyectos que tienden a mover a esa gran masa neutra vitoriana, que simpatizando con ella, no se decide a engrosar sus filas.

Asimismo, otra de las principales carencias de la UP fue la ausencia de un programa y un discurso político bien definido que fuera más allá de las consignas del conservadurismo como la defensa de la propiedad y la religión, el patriotismo, etc. y el incondicional apoyo a las políticas de Primo de Rivera. Cuestión que ya fue adelantada desde El Porvenir Agrario, portavoz del SCAA en $1925^{47}$ :

...la Unión Patriótica carece de programa (...). Un partido así, de amplia base y no definitivo, puede temerse (...) que al llegar la diferen-

«Inteligente, activo, enérgico y recto, espíritu de justicia. Llenaría muy bien su cometido. Sería excelente gobernador y haría buen papel en Logroño, Santander, Navarra, Ávila, Burgos, Álava y Guipúzcoa». AHN. Gobernación. Leg. 37 A y 61 A; el duro discurso de Tomás Hernández en el Ayuntamiento de Vitoria y la censura a la gestión pública en $\mathrm{He}$ raldo Alavés. 21-VI-1926; Rivera y De Pablo, 2014, pp. 318-319.

45 Tomás Alfaro dejó las siguientes impresiones sobre él: «hombre de mundo, lleno de simpatía, bilbaíno arruinado a quien la situación sacó a flote. (...) Se hizo querer enseguida por sus dotes especiales de convivencia, hasta el punto de que se quedó a vivir en la ciudad, después de su cese, en 1930, y durante la República, sin que nadie le repeliera (...) su gestión, se limitó a ir tirando (...) sin perseguir a nadie (...) dejó amigos, al cesar, en todos los sectores políticos». Alfaro, 1995, p. 73.

46 Amézola, 1929, pp. 44-45.

47 El Porvenir Agrario. N. ${ }^{\circ} 40$. 
ciación de matices y opiniones se descomponga violentamente por querer cada grupo que prevalezca su programa con mengua de los demás, introduciéndose de esta manera la discordia en la masa que ahora aparece tan unida y compacta.

(...)

No se diga que la «Unión Patriótica» cuenta con el asentimiento entusiasta de las multitudes: el entusiasmo es relativamente fácil en el actual estado amorfo del partido y no creo que el asentimiento llegue aun hoy a la unanimidad moral; aparte de que sabemos de sobra que las muchedumbres son versátiles y se ha reproducido muchas veces en la historia la escena del pueblo que el Domingo de Ramos aclamaba a Jesús y a los cinco días pidió su muerte.

No obstante, a pesar de todos estos problemas, la UP ofrece unos rasgos novedosos con respecto a la vida política alavesa hasta aquellos momentos: la creación de una sección femenina y una juvenil, que comenzaron a organizarse en septiembre de 1928 en torno a un pequeño grupo de jóvenes de clase media-alta vitorianos ${ }^{48}$. Fueron presididas respectivamente por María Urigüen, esposa de Ladislao de Amézola, y Francisco Javier Landaburu. Sin embargo, sus actividades fueron muy escasas y no se formó sección alguna fuera de Vitoria, dimitiendo Landaburu al poco, desentendiéndose de la UP y renunciando a la concejalía suplente del Consistorio vitoriano para la que había sido nombrado, siendo sustituido por el abogado Jaime Ozores ${ }^{49}$.

En cuanto a la función de suministrar personal político para las principales instituciones, la UP fracasó, desenvolviéndose el Ayuntamiento de Vitoria en una constante inestabilidad. Mientras que la Diputación sí que tuvo una estabilidad, siendo copada por upetistas a partir de 1927, pero se desenvolvió lánguidamente a lo largo de aquellos años ${ }^{50}$.

Con respecto a las actividades a favor de la Dictadura, la UP se encargaría en septiembre de 1926 de organizar el plebiscito a favor del régimen y la creación de la Asamblea Nacional Consultiva (ANC) en el $3^{\text {er }}$ aniversario del golpe de Estado, consistente en una recogida de firmas en plie-

48 Heraldo Alavés. 3-IX-1928; sobre las Juventudes de la UP, Quiroga, 2005, pp. 69-96.

${ }^{49}$ Heraldo Alavés. 2-I-1929; Landaburu se pasaría al nacionalismo vasco, del que sería uno de sus líderes y diputado a Cortes por el Partico Nacionalista Vasco durante la II República. Por su parte, Ozores sería miembro del partido monárquico Renovación Española.

50 Rivera, 1992, pp. 285-288. 
$\operatorname{gos}^{51}$. No obstante, las afirmaciones de Primo de Rivera de que «las autoridades (...) sin influir de modo directo y menos coactivo, faciliten todos los auxilios convenientes y necesarios para que pueda ser expresada y recogida, con mayor libertad y garantía, la opinión pública nacional» ${ }^{52}$, las coacciones y el fraude quedaron de manifiesto. En el caso de la recogida de firmas, que oficialmente fueron 42.178, una parte de estas se estamparon en Vitoria de la siguiente manera ${ }^{53}$ :

Damas muy respetables de la sociedad vitoriana, imponiéndose un sacrificio más en su nuevo aspecto social, han recorrido domicilios y talleres, ayer y hoy, recogiendo firmas de ciudadanos de ambos sexos que, sin vacilar, estamparon sus nombres uno por uno en presencia de damas y superiores, como adictos al actual régimen gubernativo. También fueron visitados los distintos centros benéficos y tanto en éstos como en los domicilios y en talleres y fábricas, la labor de las distinguidas damas fue muy fructífera.

La Iglesia también se movilizó en su favor y en ciertas localidades se realizaron visitas casa por casa, firmó la totalidad del vecindario o el número de rúbricas fue superior al censo de firmantes, ofreciéndose en este último caso la explicación de que «En algunos [pueblos] aparece algún voto más que el número de vecinos capacitados; detalle comprensible teniendo en cuenta que son aquellos en que hay colonia veraniega ${ }^{54}$.

A lo largo de los años siguientes, la UP también organizó el envío a Madrid de afiliados y somatenistas para las celebraciones del $5 .^{\circ}$ aniversario del golpe de Estado, realizó mítines y conferencias en toda la provincia para transmitir a la población las bondades y valores de la Dictadura, denunciar las actividades de la oposición e intentar captar nuevos seguidores $^{55}$. Sin embargo, parece que la asistencia del vecindario en estos ac-

${ }^{51}$ La ANC era un remedo de Parlamento de elección corporativa que aconsejaría al Gobierno sobre ciertas materias. Heraldo Alavés. 4, 6 y 9-IX-1926; sobre la ANC González Calleja, 2005, pp. 138-147; Gómez Navarro, 1991, pp. 261-304; Ben-Ami, 2012, pp. 195-221.

${ }^{52}$ La Libertad. 4-IX-1926.

53 La Libertad. 11-IX-1926; el número de firmas en Unión Patriótica. 1-X-1926.

${ }_{54}$ Heraldo Alavés. 15-IX-1926; la totalidad de firmas en algunas localidades del municipio de Nanclares de la Oca en Heraldo Alavés. 14-IX-1926; las visitas casa por casa en la localidad de Amurrio encabezadas por el alcalde, «que sabe atar bien los cabos», en $\mathrm{He}$ raldo Alavés. 15-IX-1926; el apoyo eclesiástico en Heraldo Alavés. 11-IX-1926.

55 La Libertad. 15-II-1927; 13-IX-1929; Heraldo Alavés. 16 y 17-V-1927; 20, 22 у 28-VIII-1928; 10 y 11-IX-1928; 13 y 16-IX-1929; Unión Patriótica. 1-X-1928. 
tos era más bien impuesta por la convocatoria de las autoridades, con unos apoyos más fingidos que sinceros. Así, por ejemplo, en la localidad de Salinas de Añana, se realizó un mitin en agosto de 1928 en el que su alcalde convocó al vecindario con las siguientes palabras ${ }^{56}$ :

Con el fin de dar toda la brillantez posible al acto ruego encarecidamente al vecindario su asistencia a la sala consistorial de esta villa donde deben todas las clases congregarse, sin que falten las mujeres, mostrando su entusiasmo con la expresión sincera que les caracteriza.

Confío en vuestra asistencia dados los sentimientos patrios de los habitantes de este pueblo.

Finalmente, la Dictadura cayó en enero de 1930 con la dimisión de Primo de Rivera, fruto de un cúmulo de factores, como el fracaso de su legitimización e institucionalización, su incapacidad para presentar un proyecto político bien definido y sólido, el inicio de la crisis económica de 1929, las protestas estudiantiles, las continuas conspiraciones cívico-militares en su contra y la retirada de la confianza y el apoyo de Alfonso XIII, una parte del Ejército y de las clases medias y altas por sus políticas en materia militar, económica y socio-laboral, definidas sobre el favoritismo, el autoritarismo, el corporativismo, el paternalismo y el intervencionismo estatal.

El Somatén y la UP fueron los instrumentos usados por parte de la Dictadura para movilizar a sus apoyos y proveer de personal político adicto las instituciones locales y provinciales. Ambas organizaciones fueron impulsadas desde el poder, lo que en un principio ayudó a su establecimiento. No obstante, en cuanto a sus actuaciones, en el caso del Somatén, sin peligros revolucionarios o de orden público graves a la vista, poco tenían que ver con sus objetivos originales, teniendo su reclutamiento más éxito en el mundo rural, más conservador social y políticamente, que en Vitoria. Por su parte, la UP fue incapaz de ofrecer estabilidad al Consistorio vitoriano, mientras que en los ayuntamientos rurales las antiguas élites la coparon, dando al traste con el discurso regeneracionista y anticaciquil de la Dictadura. De hecho, liberales, carlistas, republicanos y socialistas continuaron, aunque de manera limitada, sus actividades públicas, impidiendo el monopolio de la UP en la esfera pública y la política provin-

56 ATHA. DHH. FSA-005-222. 
cial ${ }^{57}$. Asimismo, la UP tampoco pudo ensanchar sus filas hacia otros sectores más allá de los ultraconservadores o de crear lealtades políticas exclusivas hacia la Dictadura en número suficiente.

Por ello, la UP y el Somatén no sobrevivirían mucho tiempo a la caída de la Dictadura. En plena descomposición, durante la primavera de 1930 sus actividades en Álava quedaron prácticamente paralizadas ${ }^{58}$, y al fallecer Primo de Rivera en su exilio parisino en marzo de 1930, realizaron unos postreros actos de homenaje a su figura al pasar su féretro por Vitoria camino de Madrid y la organización de funerales en su recuerdo por toda la provincia ${ }^{59}$. Un mes después, se anunciaría el final de la UP alavesa, siendo sustituida por la Unión Monárquica Nacional (UMN), que agruparía, ya sin la dirección de Pérez-Agote, a los remanentes de la UP hasta la proclamación de la II República, en que mayoritariamente se dispersarían entre los diferentes partidos conservadores. Mientras que el Somatén sería finalmente disuelto, excepto en Cataluña, por el Gobierno republicano en abril de $1931^{60}$.

\section{Fuentes}

Archivo del Territorio Histórico de Álava. ATHA. Archivo Histórico Nacional. AHN. Archivo Histórico Provincial de Álava. AHPA. Archivo Municipal de Vitoria-Gasteiz. AMVG. Hemeroteca Municipal de Madrid.

57 AHPA. 27466-A; AHN. Gobernación. Leg. 50 A; Heraldo Alavés. 7-III-1924; $25-$ XI-1925; 30-I-1926; 24-VII-1926; 10-IX-1926; 12-III-1927; 6 у 23-VII-1927; 26-VII1929; La Libertad. 7-II-1924; 29 y 30-IV-1924; 2-V-1924; 9, 10 y 12-II-1925; 9-IV-1925; 11-XII-1925; 6, 8, 9, 10 у 12-II-1926; 9-VI-1926; 14-II-1927; 23-I-1928; 9, 13 у 14-II1928; 5-III-1928; 14 y 30-I-1929; 11-II-1929; 27-VII-1929; 10-X-1929.

58 A los pocos días de la dimisión de Primo de Rivera, un editorial de La Libertad lo comentaba de la siguiente manera: «la vemos ya aventarse [a la UP] al primer aire de la calle, apareciendo tan sólo firmes en la perseverancia de su posición, el número escasísimo, parvo, de los que afrontan los malos tiempos, las horas adversas, porque les guió en su adhesión la buena fe, porque su impulso fue recto, aunque equivocado». La Libertad. 7-II-1930.

59 Un último manifiesto de homenaje y el paso por Vitoria del féretro en Heraldo Alavés. 17 y 20-III-1930; los funerales en Heraldo Alavés. 24, 25, 26, 27, 28 y 29-III-1930; 8 y 10-IV-1930; La Libertad. 18, 27, 28 y 29-III-1930.

${ }^{60}$ Gaceta de Madrid. 16-IV-1931; el final de la UP y el nacimiento de la UMN en $\mathrm{He}$ raldo Alavés. 2 y 3-IV-1930; 16-VI-1930; 2 y 6-VIII-1930. 


\section{Bibliografía}

Alfaro Fournier, Tomás, Una ciudad desencantada (segunda parte), Diputación Foral de Álava, Vitoria, 1995.

ALONso, Zacarías, Anuario «ZAUS», Zacarías Alonso, Vitoria, 1927.

AmÉzola, Ladislao de, El Avance de la provincia de Álava en un quinquenio (13 de septiembre de 1923-1928): memoria esquemática, Imprenta Provincial, Vitoria, 1929.

ARANA, Ignacio de Loyola, El monarquismo en Vizcaya durante la crisis del reinado de Alfonso XIII, Ediciones Universitarias de Navarra, Pamplona, 1982.

Ben-Ami, Shlomo, El cirujano de hierro. La dictadura de Primo de Rivera (19231930), RBA, Barcelona 2012.

Pablo, Santiago de, GOÑI, Joseba y LóPez de Maturana, Virginia. La Diócesis de Vitoria 150 años de Historia (1862-2012), ESET, Vitoria, 2013.

Gómez Navarro, José Luis, El régimen de Primo de Rivera. Reyes, dictaduras y dictadores, Cátedra, Madrid, 1991.

GonZÁlez CALleja, Eduardo, «La defensa armada del «orden social» durante la Dictadura de Primo de Rivera (1923-1930)», en VVAA. España entre dos siglos (1875-1931). Continuidad y cambio, Siglo XXI, Madrid, 1991, pp. 61-108.

GonZÁlez Calleja, Eduardo y Rey Reguillo, Fernando del, La defensa armada contra la revolución. Una historia de las guardias cívicas en la España del siglo XX, CSIC, Madrid, 1995.

GonzÁlez Calleja, Eduardo. La España de Primo de Rivera. La modernización autoritaria, 1923-1930, Alianza, Madrid, 2005.

GONZÁlEz CALLEJA, Eduardo, El máuser y el sufragio. Orden público, subversión y violencia política en la crisis de la Restauración (1917-1931), CSIC, Madrid, 1999.

González Calvet, María Teresa, La Dictadura de Primo de Rivera. El Directorio Militar, Ediciones el arquero, Madrid, 1987.

Pérez Agote, J. Joaquín, Un caso de responsabilidad. El acta de Laguardia. Pidiendo justicia, Sucesores de R. Velasco, Madrid, 1923.

Quiroga, Alejandro, «Perros de paja: las Juventudes de la Unión Patriótica», Ayer, n. ${ }^{\circ}$ 59, 2005, pp. 69-96.

Quiroga, Alejandro, Haciendo españoles. La nacionalización de las masas en la Dictadura de Primo de Rivera, Centro de Estudios Políticos y Constitucionales, Madrid, 2008.

Rivera, Antonio, La ciudad levítica. Continuidad y cambio en una ciudad del interior (Vitoria, 1876-1936), Diputación Foral de Álava, Vitoria, 1992.

Rivera, Antonio y De PABlo, Santiago, Profetas del pasado. La conformación de una cultura política. III. Las derechas en Álava, Ikusager, Vitoria, 2014. 
SAnZ Legaristi, Pedro María, Elecciones Municipales de 1931 en Vitoria, Diputación Foral de Álava, Vitoria, 1985.

Sanz Legaristi, Pedro y Reboredo OlivenZA, Daniel, «El sindicalismo agrario en Álava (1905-1924)», Cuadernos de Cultura, n. ${ }^{\circ}$ 8, 1985, pp. 90-104.

VÉlez CASTRILlo, Rodolfo, «Vida política en Miranda de Ebro: de la Restauración a la Segunda República (1875-1936)», Estudios Mirandeses. Anuario de la Fundación Cultural Profesor Cantera, n. 33, 2018, pp. 1-654.

\section{Financiación}

Esta investigación se ha realizado en el marco del proyecto PGC2018094133-B-100 (MCIU/AEI/FEDER,UE)

\section{Datos del autor}

Germán Ruiz Llano Doctor en Historia por la Universidad Complutense de Madrid. Sus publicaciones e investigaciones se centran en la época de entreguerras en el País Vasco, especialmente en el análisis y el estudio de la movilización contrarrevolucionaria del primer tercio del siglo xx y la historia militar de la Guerra Civil. 